\title{
Application of Pre-Column Labeling Liquid Chromatography for Canine Plasma-Free Amino Acid Analysis
}

\author{
Kazuo Azuma ${ }^{1, *}$, Yoshiko Hirao ${ }^{2}$, Yoshihiro Hayakawa ${ }^{2}$, Yusuke Murahata ${ }^{1}$, Tomohiro Osaki ${ }^{1}$, \\ Takeshi Tsuka ${ }^{1}$, Tomohiro Imagawa ${ }^{1}$, Yoshiharu Okamoto ${ }^{1}$ and Norihiko Ito ${ }^{1, *}$ \\ Received: 2 December 2015; Accepted: 4 January 2016; Published: 12 January 2016 \\ Academic Editor: Peter Meikle \\ 1 Department of Veterinary Clinical Medicine, Tottori University, 4-101 Koyama-minami, Tottori 680-8533, \\ Japan; ymurahata@muses.tottori-u.ac.jp (Y.M.); tosaki@muses.tottori-u.ac.jp (T.O.); \\ tsuka@muses.tottori-u.ac.jp (T.T.); imagawat@muses.tottori-u.ac.jp (T.I.); \\ yokamoto@muses.tottori-u.ac.jp (Y.O.) \\ 2 Analytical and Measuring Instruments Division, Shimadzu Corporation, 1, Nishinokyo Kuwabaracho, \\ Nakagyo-ku, Kyoto 604-8511, Japan; yoshikon@shimadzu.co.jp (Y.Hi.); yo-haya@shimadzu.co.jp (Y.Ha.) \\ * Correspondence: kazu-azuma@muses.tottori-u.ac.jp (K.A.); taro@muses.tottori-u.ac.jp (N.I.); \\ Tel./Fax: +81-857-31-5433 (K.A.); +81-857-31-6058 (N.I.)
}

\begin{abstract}
Plasma-free amino acid (PFAA) levels are a useful metric for diagnosing cancer and providing a prognosis. However, the use of analysis of PFAA levels has been limited in the veterinary medicine field. We addressed the application of liquid chromatography (LC) using a pre-column labeling technique for analysis of canine PFAA levels. This method significantly shortened the analysis time relative to conventional methods. No diurnal fluctuations were detected at 9:00 AM in most PFAA levels, and food intake increased the levels of some PFAAs, including valine, leucine, tyrosine, phenylalanine, and proline. These results indicate that LC with pre-column labeling is useful for measuring canine PFAA levels, for which time of day and interval after food intake must be taken into consideration.
\end{abstract}

Keywords: Plasma-free amino acid; pre-column labeling; liquid chromatography measurements; canine plasma amino acid levels; pre- and post-food intake

\section{Introduction}

Amino acids (AAs) are important substrates for and regulators of metabolic pathways [1]. Indeed, the balance of plasma-free (PF) AAs is disrupted in various diseases including cancer [2-5]. Moreover, a link has been reported between canine cancer and PFAA levels; plasma levels of glutamine (Gln), serine (Ser), asparagine (Asn), and alanine (Ala) were lower in dogs with malignant mammary gland tumors than in healthy animals [6], while plasma levels of threonine (Thr), proline (Pro), and Ser were reduced in canine oral malignant melanoma relative to controls [7]. These results indicate that PFAA levels are a useful metric for diagnosing canine cancer and predicting prognosis.

Several methods are available for measuring AA levels, including liquid chromatography (LC), gas chromatography, and capillary electrophoresis, among others [8]. Although LC methods coupled with optical detection are well established and highly reliable, post-column LC procedures are time-consuming [8]. In contrast, levels of free major AAs in plasma can be determined within 17 min by pre-column derivatization followed by reversed-phase high-performance (HP) LC [9]. The shortened analysis time makes this method suitable for routine investigation of large sample sets [9]. It is posited that one reason why analysis of AA doses has not expanded in veterinary clinical medicine is their complication and the long time they require. 
PFAA levels in humans are influenced by many factors, including diurnal and hormonal fluctuations and the food ingested [10-13]. To our knowledge, however, there are no reports describing the effects of diurnal fluctuations and food intake on canine PFAA levels via a pre-column LC method. The aim of this study is to evaluate the efficiency of the pre-column LC method for canine PFAA analysis and investigate the effects of diurnal fluctuations and food intake which affect PFAA levels.

\section{Results and Discussion}

\subsection{Diurnal Fluctuations in Canine PFAA Levels Measured with Pre-Column Labeling LC}

Table 1 indicates characteristics of dogs included in this study. All 20 AAs in canine plasma were separated within 14 min with a cycle time of $27 \mathrm{~min}$, as seen in the chromatographs (Figure 1). Figure 1 shows chromatograms of (a) an AA standard and (b) a canine plasma sample. PFAA levels after deproteinization were under $250 \mu \mathrm{mol} / \mathrm{L}$. There were no differences in PFAA levels across experimental days.

Table 1. Characteristics of dogs included in this study.

\begin{tabular}{cccc}
\hline No. & Sex & Age (Years) & Body Weight (kg) \\
\hline 1 & Male & 4 & 12 \\
2 & Male & 11 & 11 \\
3 & Male & 9 & 13 \\
4 & Female & 9 & 11 \\
5 & Female & 5 & 10 \\
\hline
\end{tabular}

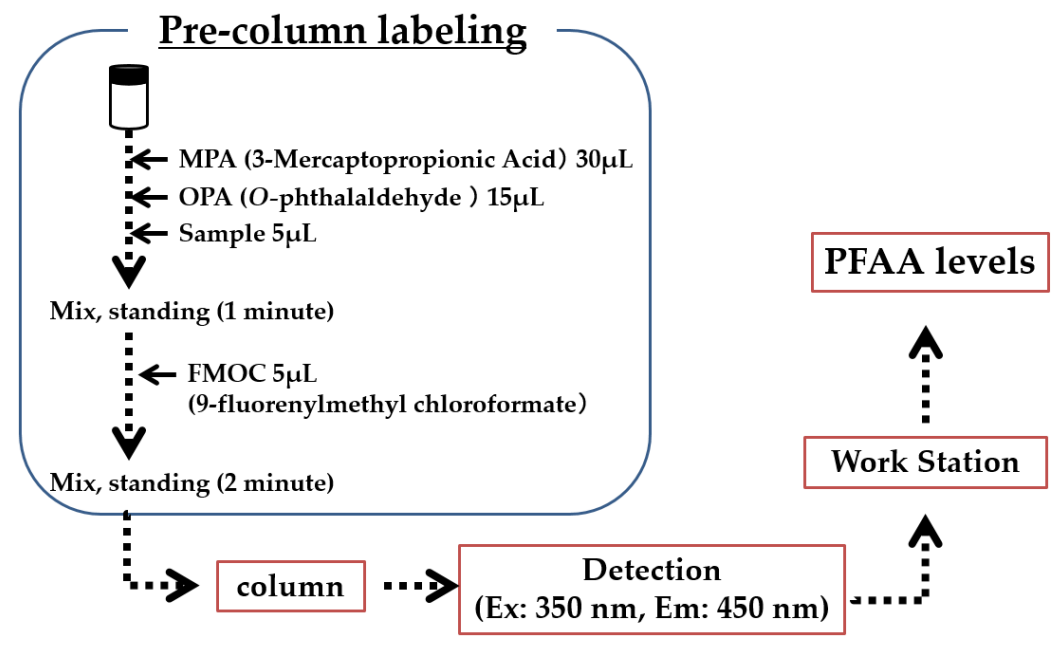

Figure 1. The schema of pre-column labeling method.

Post-column labeling techniques are sufficiently accurate for measuring canine PFAAs [14]. However, a disadvantage of this method is that it is time-consuming. For example, in our previous report, separation required $110 \mathrm{~min}$, with a cycle time of $135 \mathrm{~min}$. The pre-column method used here shortened the analysis time by a considerable margin. PFAA levels are generally constant within a certain range [10-12].

In the present study, there was no significant change in PFAA levels measured each day at 9:00 AM after a 14-h fast (Figures 2 and 3). However, standard deviations of some PFAA levels including His, Thr, Gly, Ala, and Pro were large. Our results indicate that it is true the most canine PFAA levels exhibit diurnal fluctuations. They also indicate that some hormones affects PFAA levels [15]. In facts, sex is a factor which affects PFAA levels [15]. To understand the diurnal fluctuations of plasma His, Thr, Gly, Ala, and Pro levels, a study separated into male or female is needed. It is also reported 
that PFAA levels exhibit circadian rhythm in humans [16,17]. On the other hand, it is reported that serum hydroxyproline level does not affect circadian rhythm in dogs [18]. A study must be conducted focusing on circadian rhythmicity of canine PFAA levels in the future.

(a)

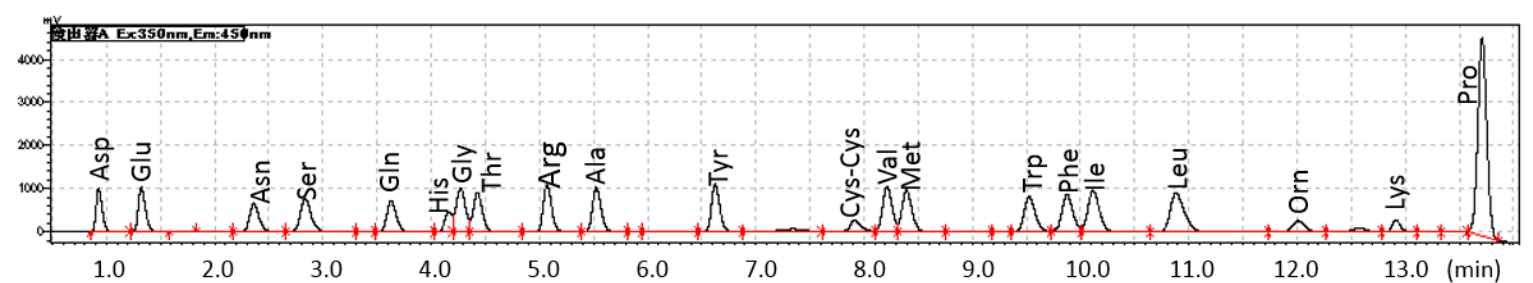

(b)

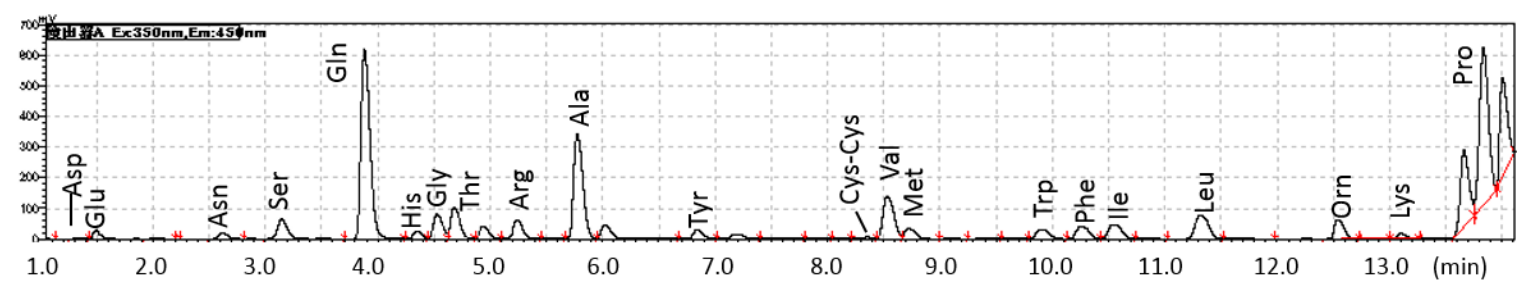

Figure 2. Representative chromatograms of (a) an AA standard and (b) a canine plasma sample. The concentration of AAs in the standard solution is $250 \mu \mathrm{mol} / \mathrm{L}$.

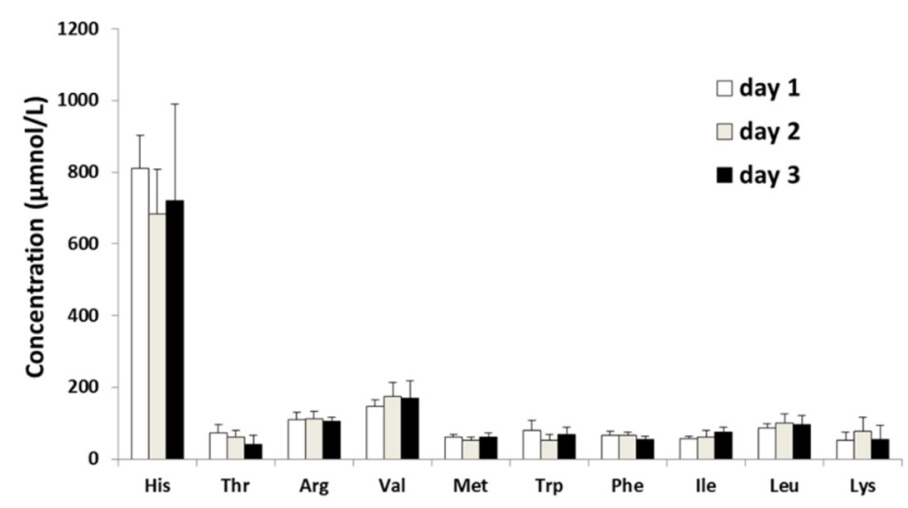

(a)

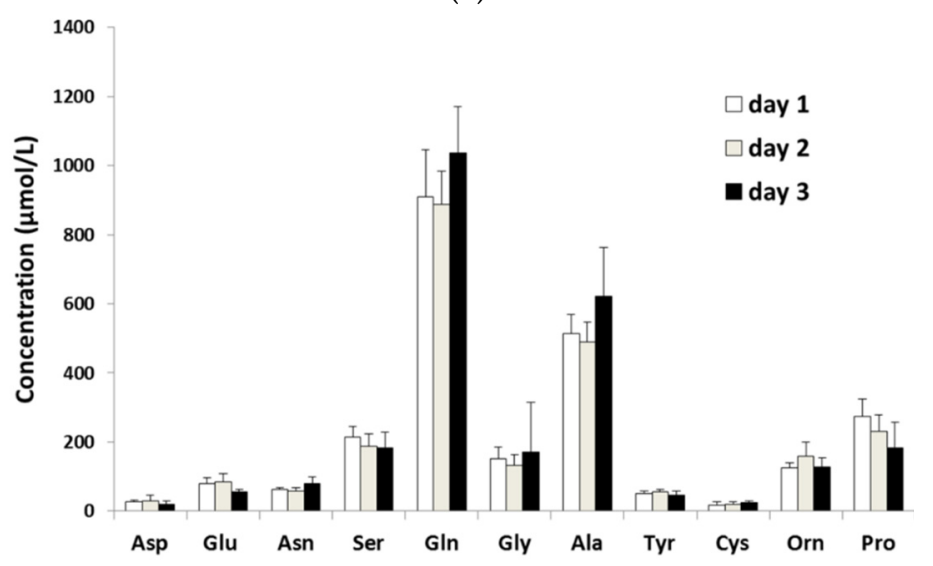

(b)

Figure 3. Diurnal fluctuations in AA concentration. Data are shown as mean \pm SD. Results for (a) essential and (b) non-essential AAs are shown. 


\subsection{Changes in PFAA Levels after Food Intake}

At 15 and 30 min after feeding, the levels of all PFAAs were equal to or slightly lower than pre-feeding levels (Table 2). At 2, 3, 4, and $6 \mathrm{~h}$ after feeding, plasma PFAA levels were increased relative to pre-feeding levels and those measured at the 15 and 30 min time points. At $2 \mathrm{~h}$ post-feeding, Leu levels were higher than before and 15 and 30 min after feeding, whereas Tyr levels were higher than at 15 and 30 min post-feeding (Figure 4). At $3 \mathrm{~h}$ after feeding, Val, Leu, Tyr, and Phe levels were increased as compared to those measured 15 and 30 min after feeding, and at 2, 3, and 4 h post-feeding, Pro levels were higher than 15 and 30 min post-feeding levels (Figure 5).

Table 2. PFAA concentrations before (Pre) and at indicated times after food intake.

\begin{tabular}{|c|c|c|c|c|c|}
\hline & Pre & $15 \mathrm{~min}$ & $30 \mathrm{~min}$ & $1 \mathrm{~h}$ & $2 \mathrm{~h}$ \\
\hline His & $803.4 \pm 88.4$ & $713.6 \pm 96.9$ & $725.2 \pm 85.3$ & $747.4 \pm 99.7$ & $844.1 \pm 184.6$ \\
\hline Thr & $66.1 \pm 27.0$ & $62.1 \pm 25.4$ & $63.9 \pm 19.7$ & $71.6 \pm 10.2$ & $96.6 \pm 16.5$ \\
\hline Arg & $110.3 \pm 21.0$ & $95.7 \pm 25.7$ & $98.2 \pm 21.1$ & $106.5 \pm 15.3$ & $123.7 \pm 34.8$ \\
\hline Val & $146.4 \pm 19.8$ & $128.8 \pm 17.5$ & $133.0 \pm 16.6$ & $164.1 \pm 43.9$ & $221.1 \pm 91.2$ \\
\hline Met & $61.4 \pm 7.4$ & $50.6 \pm 8.9$ & $55.7 \pm 7.1$ & $58.4 \pm 7.7$ & $68.3 \pm 15.3$ \\
\hline $\operatorname{Trp}$ & $79.7 \pm 26.9$ & $79.6 \pm 28.7$ & $88.1 \pm 22.2$ & $97.9 \pm 17.1$ & $111.6 \pm 27.6$ \\
\hline Phe & $67.1 \pm 11.5$ & $57.3 \pm 1.8$ & $61.8 \pm 11.4$ & $68.3 \pm 12.7$ & $81.8 \pm 16.9$ \\
\hline Ile & $56.1 \pm 7.1$ & $49.4 \pm 8.3$ & $51.0 \pm 7.8$ & $65.9 \pm 19.4$ & $84.8 \pm 38.2$ \\
\hline Leu & $86.8 \pm 11.4$ & $76.1 \pm 14.7$ & $84.4 \pm 14.9$ & $119.5 \pm 37.7$ & $171.3 \pm 74.6$ \\
\hline Lys & $51.3 \pm 23.2$ & $36.1 \pm 7.3$ & $35.8 \pm 5.2$ & $45.2 \pm 18.4$ & $52.6 \pm 42.2$ \\
\hline Asp & $26.8 \pm 4.9$ & $22.9 \pm 8.8$ & $23.4 \pm 3.9$ & $22.8 \pm 4.5$ & $27.9 \pm 11.2$ \\
\hline Glu & $80.6 \pm 16.2$ & $84.3 \pm 8.8$ & $74.5 \pm 11.7$ & $70.8 \pm 5.0$ & $79.2 \pm 20.4$ \\
\hline Asn & $62.1 \pm 6.0$ & $67.6 \pm 32.2$ & $58.8 \pm 12.9$ & $74.3 \pm 13.0$ & $92.9 \pm 27.0$ \\
\hline Ser & $214.9 \pm 29.4$ & $182.7 \pm 12.3$ & $201.5 \pm 31.7$ & $188.2 \pm 16.7$ & $207.5 \pm 42.0$ \\
\hline Gln & $909.1 \pm 137.1$ & $779.7 \pm 119.0$ & $779.0 \pm 105.6$ & $752.1 \pm 82.7$ & $834.1 \pm 205.9$ \\
\hline Gly & $157.2 \pm 30.1$ & $135.4 \pm 25.2$ & $143.2 \pm 31.0$ & $142.7 \pm 23.4$ & $159.3 \pm 19.7$ \\
\hline Ala & $514.3 \pm 55.1$ & $452.9 \pm 55.4$ & $465.3 \pm 70.3$ & $490.1 \pm 38.4$ & $578.0 \pm 160.0$ \\
\hline Tyr & $50.0 \pm 8.5$ & $42.0 \pm 8.3$ & $40.5 \pm 5.6$ & $54.0 \pm 9.6$ & $68.2 \pm 15.6$ \\
\hline Cys & $17.7 \pm 9.4$ & $14.3 \pm 7.4$ & $12.5 \pm 1.7$ & $14.8 \pm 1.7$ & $17.5 \pm 5.3$ \\
\hline \multirow[t]{2}{*}{ Pro } & $273.3 \pm 50.3$ & $244.4 \pm 39.7$ & $252.1 \pm 40.9$ & $285.7 \pm 56.2$ & $402.3 \pm 160.1$ \\
\hline & $3 \mathrm{~h}$ & $4 \mathrm{~h}$ & $6 \mathrm{~h}$ & $8 \mathrm{~h}$ & $24 \mathrm{~h}$ \\
\hline His & $776.7 \pm 139.2$ & $687.7 \pm 109.2$ & $809.0 \pm 111.2$ & $807.9 \pm 100.9$ & $665.3 \pm 116.2$ \\
\hline Thr & $92.8 \pm 36.5$ & $73.9 \pm 24.4$ & $67.2 \pm 18.8$ & $61.8 \pm 17.8$ & $57.7 \pm 20.1$ \\
\hline Arg & $122.8 \pm 37.9$ & $108.9 \pm 22.4$ & $113.3 \pm 24.5$ & $110.9 \pm 9.5$ & $112.3 \pm 20.6$ \\
\hline Val & $258.3 \pm 20.60$ * & $220.6 \pm 48.1 *$ & $191.3 \pm 27.4$ & $166.5 \pm 27.7$ & $174.3 \pm 39.0$ \\
\hline Met & $40.7 \pm 24.5$ & $54.8 \pm 24.5$ & $64.9 \pm 7.8$ & $63.9 \pm 12.9$ & $51.8 \pm 12.9$ \\
\hline $\operatorname{Trp}$ & $104.2 \pm 12.94$ & $110.8 \pm 12.97$ & $111.1 \pm 27.3$ & $98.5 \pm 26.5$ & $52.4 \pm 26.6$ \\
\hline Phe & $87.5 \pm 21.1^{*}$ & $79.3 \pm 7.2 *$ & $74.9 \pm 9.1$ & $68.1 \pm 8.4$ & $66.2 \pm 10.1$ \\
\hline Ile & $87.3 \pm 43.1$ & $77.3 \pm 43.1$ & $66.0 \pm 11.0$ & $55.7 \pm 6.9$ & $62.3 \pm 6.93$ \\
\hline Leu & $167.5 \pm 69.3 *$ & $150.7 \pm 69.8 *$ & $128.7 \pm 13.0$ & $107.1 \pm 16.2$ & $101.3 \pm 16.2$ \\
\hline Lys & $86.3 \pm 16.1$ & $94.4 \pm 16.3$ & $102.6 \pm 68.4$ & $93.4 \pm 52.6$ & $78.4 \pm 52.6$ \\
\hline Asp & $31.3 \pm 10.6$ & $25.1 \pm 7.8$ & $29.3 \pm 10.3$ & $32.8 \pm 13.6$ & $29.0 \pm 13.6$ \\
\hline Glu & $91.5 \pm 40.0$ & $70.9 \pm 41.5$ & $79.4 \pm 17.5$ & $83.1 \pm 14.8$ & $85.1 \pm 14.8$ \\
\hline Asn & $91.7 \pm 14.8$ & $93.1 \pm 14.8$ & $94.7 \pm 24.4$ & $84.5 \pm 14.6$ & $58.3 \pm 14.8$ \\
\hline Ser & $215.9 \pm 14.66$ & $211.7 \pm 14.62$ & $240.4 \pm 45.5$ & $238.2 \pm 31.4$ & $186.5 \pm 31.4$ \\
\hline Gln & $812.7 \pm 31.46$ & $817.8 \pm 31.41$ & $831.0 \pm 94.6$ & $814.8 \pm 64.2$ & $887.3 \pm 95.8$ \\
\hline Gly & $160.0 \pm 95.8$ & $171.7 \pm 95.8$ & $185.8 \pm 40.3$ & $181.7 \pm 30.3$ & $139.9 \pm 30.3$ \\
\hline Ala & $538.2 \pm 130.5$ & $485.8 \pm 130.4$ & $500.1 \pm 41.6$ & $458.4 \pm 38.8$ & $489.1 \pm 38.8$ \\
\hline Tyr & $71.2 \pm 38.8$ & $66.0 \pm 38.8$ & $64.9 \pm 12.0$ & $63.2 \pm 11.5$ & $56.2 \pm 11.7$ \\
\hline Cys & $18.5 \pm 2.3$ & $21.0 \pm 11.5$ & $16.9 \pm 2.3$ & $16.4 \pm 4.3$ & $19.8 \pm 7.4$ \\
\hline Pro & $442.9 \pm 117.7$ & $437.1 \pm 117.7$ & $442.8 \pm 44.0$ & $398.0 \pm 51.3$ & $229.9 \pm 51.3$ \\
\hline
\end{tabular}




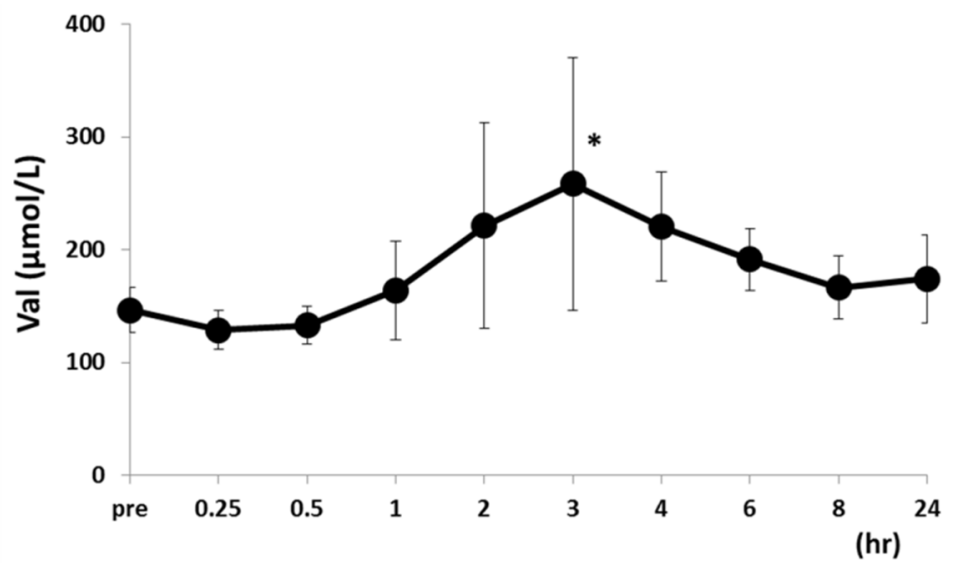

(a)

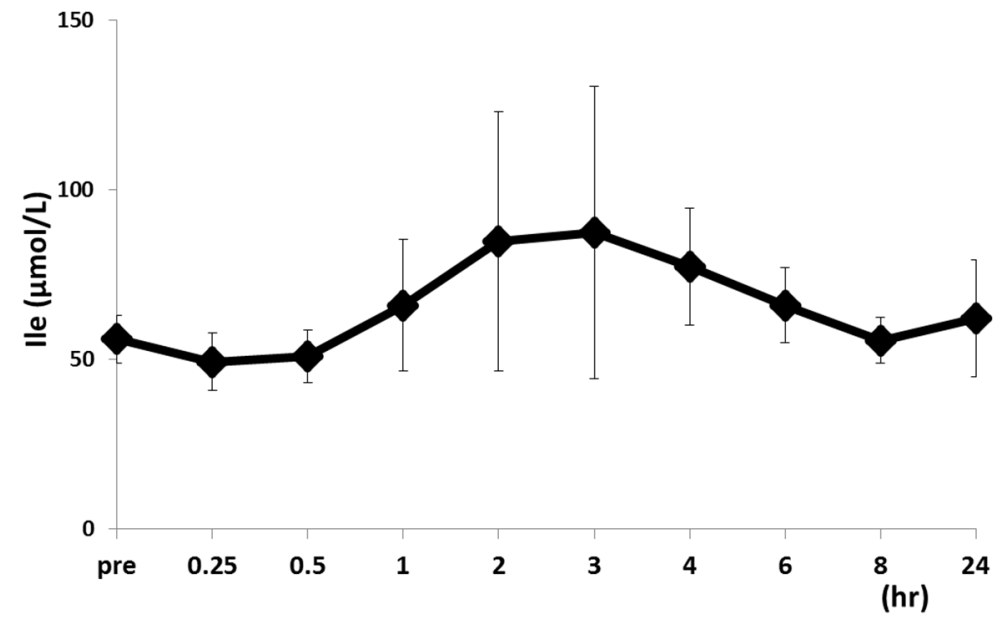

(b)

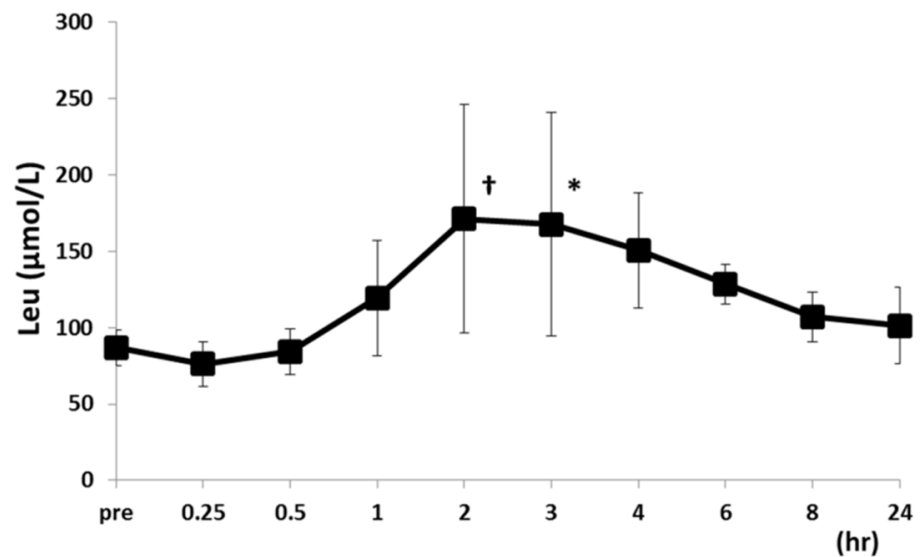

(c)

Figure 4. Changes in Val (a); Ile (b); and Leu (c) concentrations after food intake. Data are shown as mean \pm SD. ${ }^{*} p<0.05$ vs. 15 and 30 min post-food intake. ${ }^{\dagger} p<0.05$ vs. pre-food intake. 


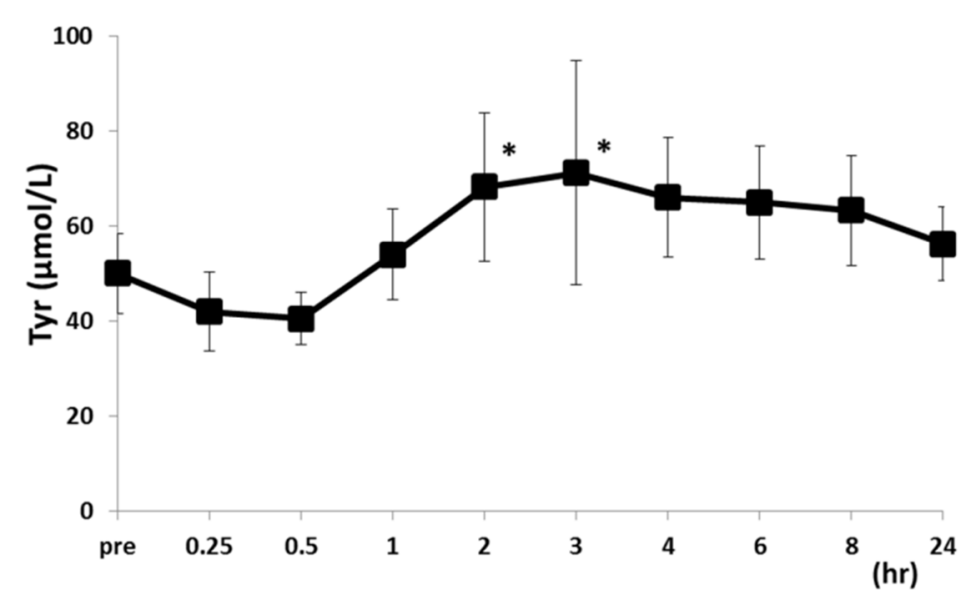

(a)

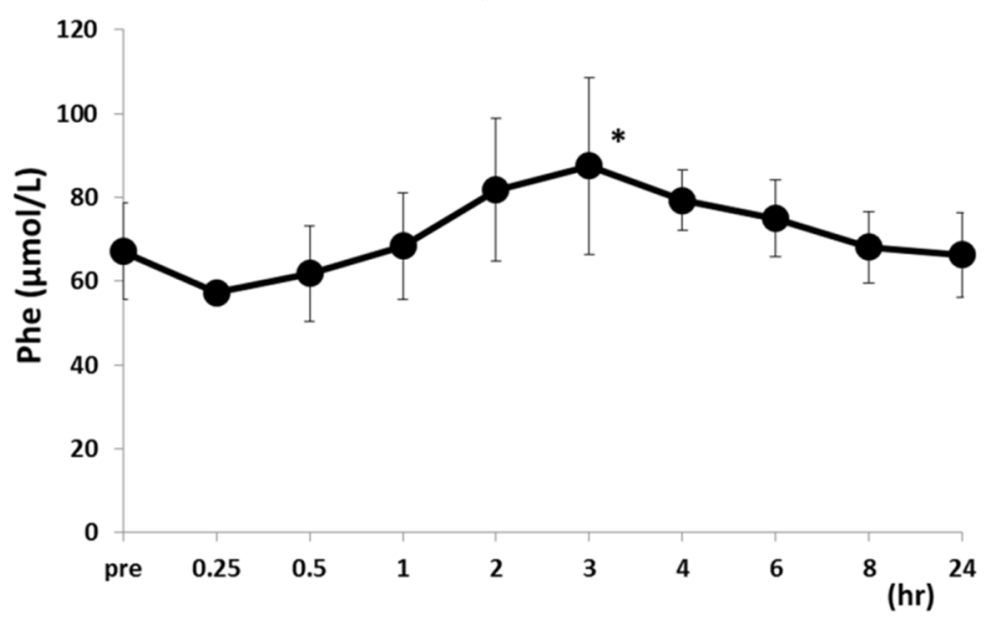

(b)

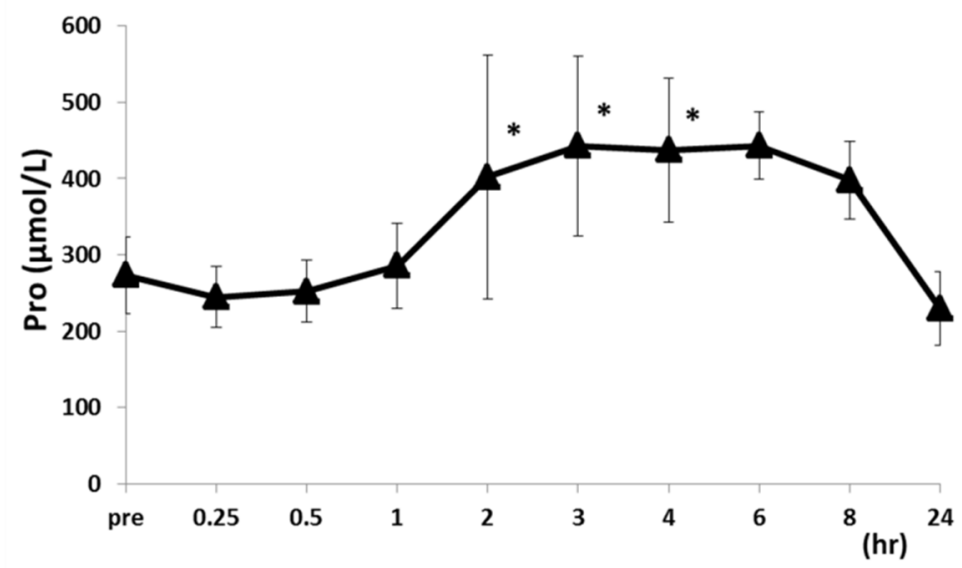

(c)

Figure 5. Changes in Tyr (a); Phe (b) and Pro (c) concentrations after food intake. Data are shown as mean \pm SD. ${ }^{*} p<0.05$ vs. 15 and 30 min post-food intake.

Food intake is a major factor affecting PFAA levels. We previously reported that intake of $500 \mathrm{mg} / \mathrm{kg}$ glucose or D-glucosamine hydrochloride decreased canine plasma Glu, Gly, and Ala levels [19]. On the other hand, a high-protein diet increases PFAA levels [10-13,20,21]) even when measured the morning after food intake [20], indicating that plasma levels of non-essential AAs were not at all (Ser, Gln, Gly, Ala, and Cys) or only slightly (Asn, Glu, and Pro) elevated, whereas those 
of essential (E) AAs (The, Val, Ile, Leu, and Lys) were increased after ingestion of a high-protein meal. Val levels are also correlated with protein intake [22]. We found that plasma EAA levels were increased after food intake, with changes in Tyr, Phe, and Pro levels observed within $8 \mathrm{~h}$. These results indicate that food intake must be considered for blood collection in analysis of canine PFAA levels. PFAA levels can vary according to many factors, including ingested AAs originating from dietary protein, protein digestibility, and the amount of free AAs [22,23]. However, ours is the first study demonstrating these effects in dogs. In previous human reports, it is found that PFAA levels increase after several hours of food intake [22,23]. Hutchison et al. reported gastrointestinal hormone, insulin, and glucagon are reacted at $40 \mathrm{~min}$ after whey protein intakes [24]. To our knowledge, there are few studies which investigate PFAA levels within an hour after food intake. Further studies should be conducted on the effect on homeostasis of acute load-dependent effects of food intake. Plasma Tyr and Phe levels are increased by the intake of food, especially protein. For example, plasma and brain levels of branched chain and aromatic AAs, as well as those of other AAs such as Pro, were increased by food intake in rats [25]. These changes may affect brain metabolism, including serotonin and catecholamine synthesis [11]. Our results suggest that this could occur after a single intake of food.

PFAA levels are regulated not only by food intake but also by hormones, organ metabolism, and disease [26,27]. Some reports have described alterations in PFAA levels in dogs as a result of diseases such as sepsis [14], diarrhea [28], and mammary gland tumors [6]. Further studies must be performed to investigate the relationships between PFAA levels and other factors including hormones and diseases.

More recently, more rapid and convenient methods for PFAA analysis have been developed. Joyce et al. also reported a method [29]. More rapid and comprehensive methods have also been recently described [30]. Their methods do not require pre-column derivatization of amino acids. The efficiency of these methods in veterinary medicine should also be investigated.

\section{Experimental Section}

\subsection{Animals}

We used five beagles ( 2 males and 3 females, 4-11 years old, body weight: $8-12 \mathrm{~kg}$ ) in this study (Table 1). The animals were reared in a room with temperature and humidity maintained at $22{ }^{\circ} \mathrm{C} \pm 2{ }^{\circ} \mathrm{C}$ and $50 \% \pm 5 \%$, respectively, on a 12:12-h light/dark cycle (lights on at 7:00 AM). Experimental procedures involving the dogs were approved by the Animal Research Committee of Tottori University.

\subsection{Sample Collection and Processing}

Dogs were fed commercial food (70 kcal/kg body weight; Cainz Co., Honjo, Japan) until 7:00 PM. The food consisted of $1380.2 \mathrm{~kJ}$ of energy (per $100 \mathrm{~g}$ ), with $22 \%$ of the energy provided by protein, $22 \%$ as fat, and $56 \%$ as carbohydrates. Blood samples $(2 \mathrm{~mL})$ were initially collected at 9:00 AM (pre; day 1); thereafter, dogs were fed commercial food ( $50 \mathrm{kcal} / \mathrm{kg}$ body weight), and blood $(2 \mathrm{~mL})$ was collected $0.25,0.5,1,2,3,4,6$, and $8 \mathrm{~h}$ after food intake. After all blood samples were obtained on day $1, \operatorname{dogs}$ were fed commercial food ( $20 \mathrm{kcal} / \mathrm{kg}$ body weight). The following day ( $24 \mathrm{~h}$ after food intake) and on days 7 and 14 (hereafter referred to as days 2 and 3, respectively), blood was collected at 9:00 AM. Dogs had free access to fresh water during the experimental period.

Blood was obtained from the jugular vein and fed into tubes containing heparin and immediately separated by centrifugation at $1700 \times g$ for $10 \mathrm{~min}$ at $4{ }^{\circ} \mathrm{C}$. Plasma was promptly removed and frozen at $-80^{\circ} \mathrm{C}$ until PFAA measurements. The plasma was deproteinized in methanol (plasma:methanol $(v / v)=1: 9)$ for $20 \mathrm{~min}$; samples were then centrifuged at $15,000 \times \mathrm{g}$ for $10 \mathrm{~min}$ at $4{ }^{\circ} \mathrm{C}$, and precipitated proteins were removed. 


\subsection{PFAA Measurements}

All regents, including standard AA solutions (type $\mathrm{H}$ ), were purchased from Wako Pure Chemical Industries (Osaka, Japan). We used a LC system with automated Pre-column derivatization functionality (Nexera X2; Shimadzu, Kyoto, Japan). The following basic AAs and related molecules (a total of 20 compounds) were measured and used in the analysis: Ala, arginine (Arg), Asn, cysteine-cysteine (Cys-Cys), glutamic acid (Glu), Gln, glycine (Gly), histidine (His), isoleucine (Ile), leucine (Leu), lysine (Lys), methionine (Met), phenylalanine (Phe), Pro, Ser, Thr, tryptophan (Trp), tyrosine (Tyr), and valine (Val). Standard AA solution in this study was prepared by standard AA solution (type H), Asn, Gln, Trp and Orn were diluted 5\% of $\mathrm{HCl}$ (each concentration of AA is $250 \mu \mathrm{mo} / \mathrm{L}$.

A summary of the labeling of amino acids is shown in Figure 1. At first, $0.1 \mathrm{~mol} / \mathrm{L}$ boric acid solution was prepared by dissolving boric acid $(0.31 \mathrm{~g})$ and $\mathrm{NaOH}(0.1 \mathrm{~g})$ in diluted water (50 mL). 3-Mercaptopropionic Acid (MPA) solution were prepared by dissolving $10 \mu \mathrm{L}$ of MPA in boric acid solution $(10 \mathrm{~mL})$. O-phthalaldehyde (OPA) solution was prepared by dissolveing OPA $(10 \mathrm{mg})$ in ethanol $(0.3 \mathrm{~mL})$, boric acid solution $(0.7 \mathrm{~mL})$ and diluted water $(4 \mathrm{~mL})$. 9-fluorenylmethyl chloroformate (FMOC) solution was prepared by dissolving FMOC $(10 \mathrm{mg})$ in acetonitrile $(25 \mathrm{~mL})$. We used two mobile phase solution. One was $15 \mathrm{mmol} / \mathrm{L}$ potassium dihydrogenphosphate $\left(\mathrm{KH}_{2} \mathrm{PO}_{4}\right)$ and $5 \mathrm{mmol} / \mathrm{L}$ dipotassium hydrogenphosphate $\left(\mathrm{K}_{2} \mathrm{HPO}_{4}\right)$, which was prepared using dissolved $\mathrm{KH}_{2} \mathrm{PO}_{4}(2.04 \mathrm{~g})$ and $\mathrm{K}_{2} \mathrm{HPO}_{4}(0.87 \mathrm{~g})$ in diluted water $(1000 \mathrm{~mL})$. The other was a mixture of acetonitrile/methanol/diluted water $(45 / 40 / 15)$. The flow rate of the mobile phase solution was $0.8 \mathrm{~mL} / \mathrm{min}$. Injected volume was $1 \mu \mathrm{L}$. The temperature of the column oven was $35^{\circ} \mathrm{C}$. The condition of fluorescence detection was 350 (Ex.) $\mathrm{nm}$ and $450 \mathrm{~nm}$ (Em.). LabSolutions LC/GC (Shimadzu) was used as a work station. Each PFAA level was detected according to the standard amino acid solution. Plasma levels of AAs are expressed in $\mu \mathrm{mo} / \mathrm{L}$.

\subsection{Statistical Analysis}

Data are expressed as mean \pm SD. Differences between groups were evaluated by one-way analysis of variance followed by Tukey-Kramer's test. A $p$-value $<0.05$ was considered statistically significant.

\section{Conclusions}

Canine PFAA levels were measured by pre-column labeling LC. This method shortened the analysis time, and there were no diurnal fluctuations in most PFAA levels when measurements were made at 9:00 AM. Food intake increased the levels of a subset of AAs including some EAAs as well as Tyr, Phe, and Pro. Our results indicate that the time of day and interval after food intake must be considered when measuring canine PFAA levels.

Acknowledgments: This work was supported by a Japan Society for the Promotion of Science Kakenhi grant (No. 15K18793).

Author Contributions: Kazuo Azuma and Norihiko Ito planned the experiments; Kazuo Azuma, Yoshiko Hirao and Yoshihiro Hayakawa performed the amino acid analysis; Kazuo Azuma and Norihiko Ito analyzed the data; Yusuke Murahata, Tomohiro Osaki, Takeshi Tsuka, Tomohiro Imagawa, and Yoshiharu Okamoto provided valuable discussions; Kazuo Azuma wrote the manuscript; all authors read and revised the manuscript; and Norihiko Ito supervised the project.

Conflicts of Interest: The authors declare no conflict of interest. 


\section{References}

1. Brosnan, J.T. Interorgan amino acid transport and its regulation. J. Nutr. 2003, 133, 2068S-2072S. [PubMed]

2. Maeda, J.; Higashiyama, M.; Imaizumi, A.; Nakayama, T.; Yamamoto, H.; Daimon, T.; Yamakado, M.; Imamura, F.; Kodama, K. Possibility of multivariate function composed of plasma amino acid profiles as a novel screening index for non-small cell lung cancer: A case control study. BMC Cancer 2010. [CrossRef] [PubMed]

3. Miyagi, Y.; Higashiyama, M.; Gochi, A.; Akaike, M.; Ishikawa, T.; Miura, T.; Saruki, N.; Bando, E.; Kimura, H.; Imamura, F.; et al. Plasma free amino acid profiling of five types of cancer patients and its application for early detection. PLoS ONE 2011, 6, e24143. [CrossRef] [PubMed]

4. Proenza, A.M.; Oliver, J.; Palou, A.; Roca, P. Breast and lung cancer are associated with a decrease in blood cell amino acid content. J. Nutr. Biochem. 2003, 14, 133-138. [CrossRef]

5. Fukutake, N.; Ueno, M.; Hiraoka, N.; Shimada, K.; Shiraishi, K.; Saruki, N.; Ito, T.; Yamakado, M.; Ono, N.; Imaizumi, A.; et al. A novel multivariate index for pancreatic cancer detection based on the plasma free amino acid profile. PLoS ONE 2015, 10, e0132223. [CrossRef] [PubMed]

6. Azuma, K.; Osaki, T.; Tsuka, T.; Imagawa, T.; Minami, S.; Okamoto, Y. Plasma free amino acid profiles of canine mammary gland tumors. J. Vet. Sci. 2012, 13, 433-436. [CrossRef] [PubMed]

7. Kawabe, M.; Baba, Y.; Tamai, R.; Yamamoto, R.; Komori, M.; Mori, T.; Takenaka, S. Profiling of plasma metabolites in canine oral melanoma using gas chromatography-mass spectrometry. J. Vet. Med. Sci. 2015, 77, 1025-1028. [CrossRef] [PubMed]

8. Kaspar, H.; Dettmer, K.; Gronwald, W.; Oefner, P.J. Advances in amino acid analysis. Anal. Bioanal. Chem. 2009, 393, 445-452. [CrossRef] [PubMed]

9. Terrlink, T.; van Leeuwen, P.A.; Houdijk, A. Plasma amino acids determined by liquid chromatography within 17 minutes. Clin. Chem. 1994, 40, 245-249. [PubMed]

10. Ashley, D.V.; Barclay, D.V.; Chauffard, F.A.; Moennoz, D.; Leathwood, P.D. Plasma amino acid responses in humans to evening meals of differing nutritional composition. Am. J. Clin. Nutr. 1982, 36, 143-153. [PubMed]

11. Fernstrom, J.D.; Wurtman, R.J.; Hammarstrom-Wiklund, B.; Rand, W.M.; Munro, H.N.; Davidson, C.S. Diurnal variations in plasma concentrations of tryptophan, tyrosine, and other neutral amino acids: Effect of dietary protein intake. Am. J. Clin. Nutr. 1979, 32, 1912-1922. [PubMed]

12. Nasset, E.S.; Heald, F.P.; Calloway, D.H.; Margen, S.; Schneeman, P. Amino acids in human blood plasma after single meals of meat, oil, sucrose and whiskey. J. Nutr. 1979, 109, 621-630. [PubMed]

13. Van Loon, L.J.; Saris, W.H.; Verhagen, H.; Wagenmakers, A.J. Plasma insulin responses after ingestion of different amino acid or protein mixtures with carbohydrate. Am. J. Clin. Nutr. 2000, 72, 96-105. [PubMed]

14. Chan, D.L.; Rozanski, E.A.; Freeman, L.M. Relationship among plasma amino acids, C-reactive protein, illness severity, and outcome in critically ill dogs. J. Vet. Intern. Med. 2009, 23, 559-563. [CrossRef] [PubMed]

15. Yamamoto, H.; Kondo, K.; Tanaka, T.; Muramatsu, T.; Yoshida, H.; Imaizumi, A.; Nagao, K.; Noguchi, Y.; Miyano, H. Reference intervals for plasma-free amino acid in a Japanese population. Ann. Clin. Biochem. 2015, in press. [CrossRef] [PubMed]

16. Riggio, O.; Merli, M.; Pieche, U.; Romiti, A.; Pasqualetti, P.; Coppola, A.; Danese, D.; Cugini, P.; Capocaccia, L. Circadian rhythmicity of plasma amino acid variations in healthy subjects. Recent. Prog. Med. 1989, 80, 591-593.

17. Tsai, P.; Wu, W.; Huong, P. Circadian variations in plasma neutral and basic amino acid concentrations in young men on an ordinary Taiwanese diet. J. Formos. Med. Assoc. 2000, 99, 151-157. [PubMed]

18. Svanberg, G.K. Biological variations in serum total hydroxyproline concentration in the beagle dog. Lab. Anim. 1988, 22, 157-161. [CrossRef] [PubMed]

19. Azuma, K.; Osaki, T.; Tsuka, T.; Imagawa, T.; Okamoto, Y.; Takamori, Y.; Minami, S. Effects of oral glucosamine hydrochloride administration on plasma free amino acid concentrations in dogs. Mar. Drugs 2011, 9, 712-718. [CrossRef] [PubMed]

20. Nishioka, M.; Imaizumi, A.; Ando, T.; Tochikubo, O. The overnight effect of dietary energy balance on postprandial plasma free amino acid (PFAA) profiles in Japanese adult men. PLoS ONE 2013, 8, e62929. [CrossRef] [PubMed]

21. Fischer, K.; Colombani, P.C.; Langhans, W.; Wenk, C. Carbohydrate to protein ratio in food and cognitive performance in the morning. Physiol. Behav. 2002, 75, 411-423. [CrossRef] 
22. Lacroix, M.; Bos, C.; Leonil, J.; Airinei, G.; Luengo, C.; Daré, S.; Benamouzig, R.; Fouillet, H.; Fauquant, J.; Tomé, D.; et al. Compared with casein or total milk protein, digestion of milk soluble proteins is too rapid to sustain the anabolic postprandial amino acid requirement. Am. J. Clin. Nutr. 2006, 84, 1070-1079. [PubMed]

23. Marrs, T.C.; Addison, J.M.; Burston, D.; Matthews, D.M. Changes in plasma amino acid concentrations in man after ingestion of an amino acid mixture simulating casein, and a tryptic hydrolysate of casein. Br. J. Nutr. 1975, 34, 259-265. [PubMed]

24. Hutchison, A.T.; Piscitelli, D.; Horowitz, M.; Jones, K.L.; Clifton, P.M.; Standfield, S.; Hausken, T.; Feinle-Bisset, C.; Luscombe-Marsh, N.D. Acute load-dependent effects of oral whey protein on gastric emptying, gut hormone release, glycemia, appetite, and energy intake in healthy men. Am. J. Clin. Nutr. 2015, in press. [CrossRef] [PubMed]

25. Fernstrom, J.D.; Faller, D.V. Neutral amino acids in the brain: Changes in response to food ingestion. J. Neurochem. 1978, 30, 1531-1538. [CrossRef] [PubMed]

26. Tremblay, F.; Lavigne, C.; Jacques, H.; Marette, A. Role of dietary proteins and amino acids in the pathogenesis of insulin resistance. Annu. Rev. Nutr. 2007, 27, 293-310. [CrossRef] [PubMed]

27. Volpi, E.; Sheffield-Moore, M.; Rasmussen, B.B.; Wolfe, R.R. Basal muscle amino acid kinetics and protein synthesis in healthy young and older men. J. Am. Med. Assoc. 2001, 286, 1206-1212. [CrossRef]

28. Dossin, O.; Rupassara, S.I.; Weng, H.Y.; Williams, D.A.; Garlick, P.J.; Schoeman, J.P. Effect of parvoviral enteritis on plasma citrulline concentration in dogs. J. Vet. Intern. Med. 2011, 25, 215-221. [CrossRef] [PubMed]

29. Joyce, R.; Kuziene, V.; Zou, X.; Wang, X.; Pullen, F.; Loo, R.L. Development and validation of an ultra-performance liquid chromatography quadrupole time of flight mass spectrometry method for rapid quantification of free amino acids in human urine. Amino Acids 2015, in press. [CrossRef] [PubMed]

30. Nemkov, T.; D’Alessandro, A.; Hansen, K.C. Three-minute method for amino acid analysis by UHPLC and high-resolution quadrupole orbitrap mass spectrometry. Amino Acids 2015, 47, 2345-2357. [CrossRef] [PubMed]

(C) 2016 by the authors; licensee MDPI, Basel, Switzerland. This article is an open access article distributed under the terms and conditions of the Creative Commons by Attribution (CC-BY) license (http://creativecommons.org/licenses/by/4.0/). 